\title{
Fabrication of Titanate Barium Films by Electrophoretic Deposition Technique
}

\author{
Maksim Zagorny", Volodymyr Pidsosonnyi, Anna Ivanchuk, Alexander Zhygotsky and Andrey Ragulya \\ Department of Physical Chemistry and Technology of Nanostructure Ceramic and Composites, Ivan Nikitovich Frantsevich Institute \\ for Problems of Materials Science of NAS of Ukraine, Kiev 03680, Ukraine
}

Received: January 16, 2014 / Accepted: January 28, 2014 / Published: March 25, 2014.

\begin{abstract}
EPD (electrophoretic deposition) technique has been shown as an effective method to produce thin ore thick layers at voltage 5-100 V onto Ni conductive substrate. The aim of this study is to use the EPD method to fabricate films from suspensions $\mathrm{BaTiO}_{3}$. The effects of the EPD process parameters such as the suspension concentration, deposition time, electrical field strength on the specific EPD deposited weight, morphology particles were used. The surface microstructures of the as-deposited films were investigated by SEM (scanning electron microscopy). A homogeneous microstructure was obtained at applied electric field of $100 \mathrm{~V}$ and $1 \mathrm{~min}$ of deposition time at an electrode distance of $1.0 \mathrm{~cm}$.
\end{abstract}

Key words: $\mathrm{BaTiO}_{3}$, suspension, $\mathrm{EPD}$, deposition time, viscosity, olygoperoxide.

\section{Introduction}

EPD (electrophoretic deposition) simple technique has been shown as an effective method to produce thin layers on to conductive substrates [1-3]. It is known that the EPD method is a versatile method to fabricate thin or thick films of both metals and ceramics on the electrode substrates. For example, the EPD technique has been used by authors to cover the termination surface of fine inner Pd-Ag electrodes (electrode width 3-4 $\mu \mathrm{m}$ ) with zinc borosilicate glass ( $\mathrm{Zn}-\mathrm{B}-\mathrm{Si}-\mathrm{O})$ powder to form insulator layers on both sides of piezoelectric PZT-PNN (( $\left.\mathrm{Pb}(\mathrm{Nb}, \mathrm{Ni}) \mathrm{O}_{3}-\mathrm{Pb}(\mathrm{Zr}, \mathrm{Ti}) \mathrm{O}_{3}\right)$ actuators [4].

Recently, the mild organic solvent such as acetone, ethanol, acetylacetone was used to prepare $\mathrm{BaTiO}_{3}$ EPD suspension [5-7]. Harari [8] formed $\mathrm{BaTiO}_{3}$ films with thickness of $10-50 \mu \mathrm{m}$ from the suspension with particles size of $200 \mathrm{~nm}$ using a mixture acetone-ethanol (2:1).

Nanostructured films of $\mathrm{BaTiO}_{3}$ [9] with the

\footnotetext{
*Corresponding author: Maksim Zagorny, Ph.D., research fields: conducting nanocomposites PANI, $\mathrm{TiO}_{2}$, polyaniline and ferroelectric films $\mathrm{BaTiO}_{3}$ E-mail: maksimmaksim@bigmir.net.
}

thickness of several microns were prepared by EPD of monodisperse powders in mixture of 2methoxyethanol-acetylacetone. Films were formed at electrode composition of $\mathrm{Pt} / \mathrm{Ti} / \mathrm{SiO}_{2}$.

High-oriented film $\mathrm{BaTiO}_{3}$ [10] were obtained on Pt electrodes by a combination of EPD and hydrothermal method. The distance between the electrodes was $4 \mathrm{~cm}$ and the area was $0.5-1 \mathrm{~cm}^{2}$. It was found that the concentration of $\mathrm{Ba}(\mathrm{OH})_{2}$ in suspension influences on the films orientation. In the region of $\mathrm{Ba}(\mathrm{OH})_{2}$ concentration of $0.08-0.1 \mathrm{~mol} \cdot \mathrm{L}^{-1}$ the orientation parameter $f=1$, and in $0.04-0.065$ $\mathrm{mol} \cdot \mathrm{L}^{-1} f<1$, respectively.

Thus, most publications on EPD have a pronounced applied nature and consider the process itself EPD powder suspensions as an auxiliary in obtaining certain materials. Stabilization of the suspension is generally regarded as being essential for attaining uniform particle-packing structure of the electrophoretic ceramic deposits. Suspension stability depends on the amount of surfactant or additive used, suspension concentration, $\mathrm{pH}$ and conductivity.

In the present study, the authors used surfactant 
functional (OP (olygoperoxide)) olygoperoxide additive of $\mathrm{BaTiO}_{3}$ nanoparticles for stable suspension fabrication in mixture acetylacetone-ethanol. In addition, to use the EPD method to fabricate $\mathrm{BaTiO}_{3}$ ferroelectric layers with as well as to investigate the effects of various EPD process on surface and morphology particles.

\section{Experiments}

\subsection{Reagents and Materials}

$\mathrm{BaTiO}_{3}$ nanoparticles $\left(19 \mathrm{~m}^{2} / \mathrm{g}\right)$ was synthesized by non-isothermic method using methodic [11]. Functional substance of OP was synthesized at Lvivsky Politechnik University of Ukraine. Ethanol, (AA (acetylacetone)) acetylacetone were obtained from Merck Chemical Reagents Company. All these reagents were used without further purification.

OP complex was obtained by reaction interaction of active vinylacetate-co-5-tret-butylperoxy-5 methyl-1hexen-3-co-maleic anhydride with $\mathrm{Cu}^{2+}$ in alcohol solution. Composition: vinylacetate-22\%; tret-butylperoxy-5-methyl-1-hexen-48\%; maleic anhydride-30\% (Fig. 1). Characteristics of OP: Molecular weight $\left(M_{w}\right)$ 2,000 $\mathrm{g} \cdot \mathrm{mol}^{-1}$, surface tension is $37.5 \mathrm{mN} \cdot \mathrm{m}^{-1}$ and content cations of $\mathrm{Cu}(\mathrm{II})$ is $1.1 \%$.

\subsection{EPD Suspensions of $\mathrm{BaTiO}_{3}$}

Pure $\mathrm{BaTiO}_{3}$ was added in $100 \mathrm{~mL}$ organic solvent mixture of acetylacetone and ethanol (1:1) using magnetic stirrer during of $15 \mathrm{~min}$. Then obtained 2 and 10 wt. $\%$ suspension of $\mathrm{BaTiO}_{3}$ was ultrasonically agitated $(\sim 10 \mathrm{~min})$. The substance OP with concentration of $0.01-0.2$ wt. $\%$ was added to suspension and mechanically treated by ball milling: The EPD suspension added to $200 \mathrm{~g}$ YSZ milling balls $(3 \mathrm{~mm} \varnothing)$ in a polyethylene container $(120 \mathrm{~mL})$ was milled at $250 \mathrm{rpm}$ for $24 \mathrm{~h}$.

For EPD, suspensions with solid concentrations of 2 , 10 wt. \% were chosen. Two Ni electrodes (90 $\mu \mathrm{m}$ thick), which were acted as a substrate (cathode) for $\mathrm{BaTiO}_{3}$ layer deposition and a counter electrode (anode), respectively, were hold by fixtures, connected to DC power supply and ammeter and submerged, in the EPD tank $(50 \mathrm{~mL})$. The EPD suspensions was carried out with applied electric field strength (5-100 V), deposition time $(60-600 \mathrm{~s})$, distance between electrodes $1 \mathrm{~cm}$. Surface area of electrodes was 2-4 $\mathrm{cm}^{2}$. After EPD process samples of green films were dried slowly up to $100{ }^{\circ} \mathrm{C}$ to prevent it from cracking.

\subsection{Characterization}

The structural investigation and phase formation of $\mathrm{BaTiO}_{3}$ were done by powder X-ray diffraction technique in a XRD-DRON $3 \mathrm{M}$, using $\mathrm{CuK} \alpha$ radiation. The measurements were carried out at room temperature in continuous mode, in the $2 \theta$ range between $20^{\circ}$ and $90^{\circ}$.

Particles size of $\mathrm{BaTiO}_{3}$ suspensions were performed by laser granulometry in nanosizer HS1000 (Malvern, United Kingdom).

Rheological properties of the nanoparticles suspensions were determined at constant temperature $\left(25{ }^{\circ} \mathrm{C}\right)$ using rheometer RN4.1 (Germany) with cylindrical nozzle of $1 \mathrm{~mm}$. All suspensions used in this study were stabilized by magnetic stirring during $30 \mathrm{~min}$.

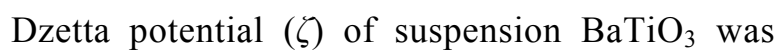

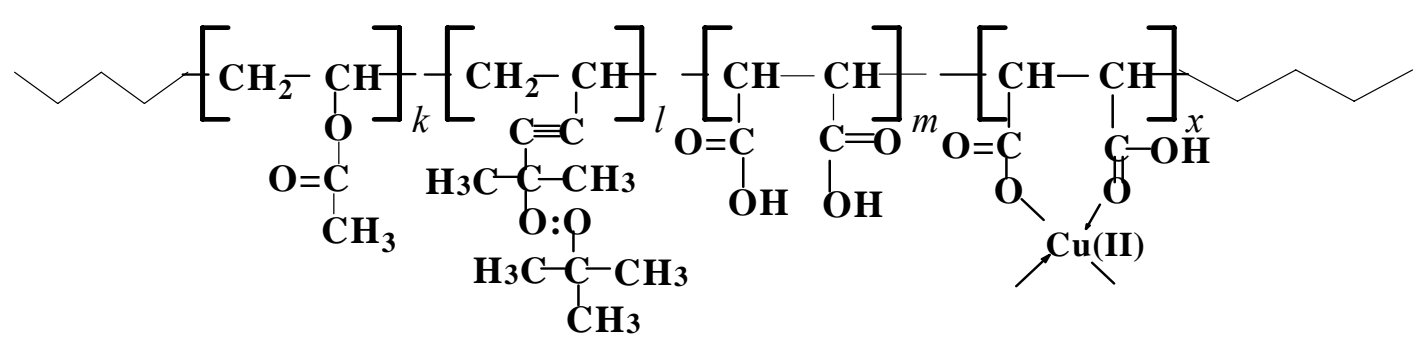

Fig. 1 Scheme chain of OP. 
determined by boundary motion using a modified device Tchaikovsky (Russia).

Conductivity of the suspensions was determined on the bridge AC P5058 (Russia) using cell with two platinum electrodes at a frequency of $1 \mathrm{kHz}$.

The morphology of $\mathrm{BaTiO}_{3}$ particles films were investigated using scanning electron microscope JSM-7600F JEOL at acceleration voltage of $200 \mathrm{kV}$.

\section{Results and Discussion}

\section{1 $\mathrm{BaTiO}_{3}$ Powder Characterization}

The XRD pattern (Fig. 1) indicates that the synthesized powder shows good agreement with the tetragonal $\mathrm{BaTiO}_{3}$ structure with the $\mathrm{P} 4 \mathrm{~mm}$ space group (JCPDS data No. 05-0626), with no impurity peak appearing in the diffractogram and lattice parameters $a=4.000 \AA, c=4.030 \AA$. These values are very close to the reported values refraining to this tetragonal structure (JCPDS data No. 05-0627). XRD pattern of synthesized $\mathrm{BaTiO}_{3}$ powders show peak at $45^{\circ}$. In general, the XRD pattern of the tetragonal $\mathrm{BaTiO}_{3}$ show split peaks at $45^{\circ}$ corresponding to the (hkl) Miller index (002) and (200). Thus, we can conclude that synthesized powder show a tetragonal or tetragonal-dominant structure with ratio of $c / a=$ 1.0075. A crystallite size of $40 \mathrm{~nm}$ was estimated by the Scherrer's equation for peak (101).

\subsection{Suspension $\mathrm{BaTiO}_{3}$ Characterization}

It is noted that the quality of electrophoretic deposition heavily depends on the suspension conditions formation. So, a well dispersed stable suspension will provide a better deposition during EPD process compared to an unstable or strong agglomerated powder suspension. The results of laser granulometry show that $\mathrm{BaTiO}_{3}$ particles are less agglomerated in a mixture of ethanol-AA (ethanol-acetylacetone) compared with pure ethanol after treatment in a ball mill (Fig. 2).

For control stability, suspension rheological test was used before EPD process with different shear rates at constant temperature. It is known that most suspensions are pseudoplastic and exhibit a decrease in viscosity with an increase in shear rate. So, the viscosity tends to decrease as a function of increasing shear rate [12]. As can been seen in Fig. 3 suspension without additive OP is pseudoplastic.

Viscosity of the suspension (Fig. 3) gradually decreases from $35 \mathrm{mPa} \cdot \mathrm{s}$ to $5 \mathrm{mPa} \cdot \mathrm{s}$ in shear rates of $0-250 \mathrm{~s}^{-1}$ then it does not change. With the introduction of small amounts of surfactant OP, the slurry becomes almost Newtonian. The viscosity remains virtually unchanged in the range of shear rates. The viscosity suspensions of $2.5-5.0 \mathrm{mPa} \cdot \mathrm{s}$ is optimal

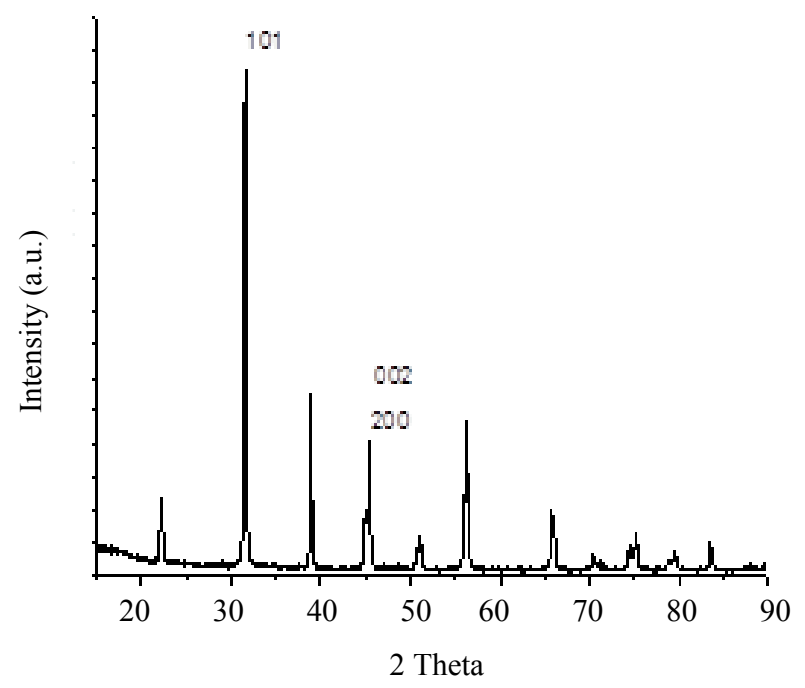

Fig. 1 XRD pattern of synthesized $\mathrm{BaTiO}_{3}$.

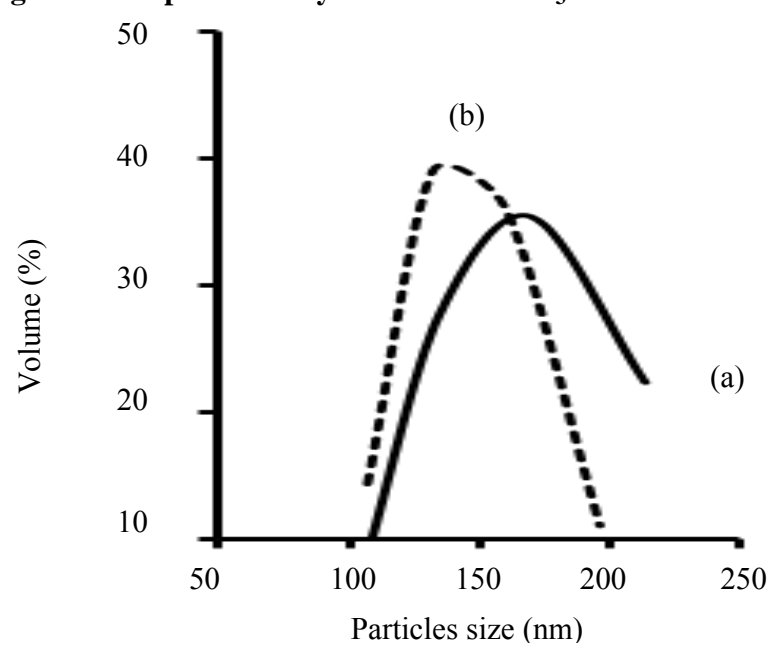

Fig. 2 Particle size distribution of the $\mathrm{BaTiO}_{3}$ suspension at different solvents: (a) ethanol; (b) ethanol: AA. 


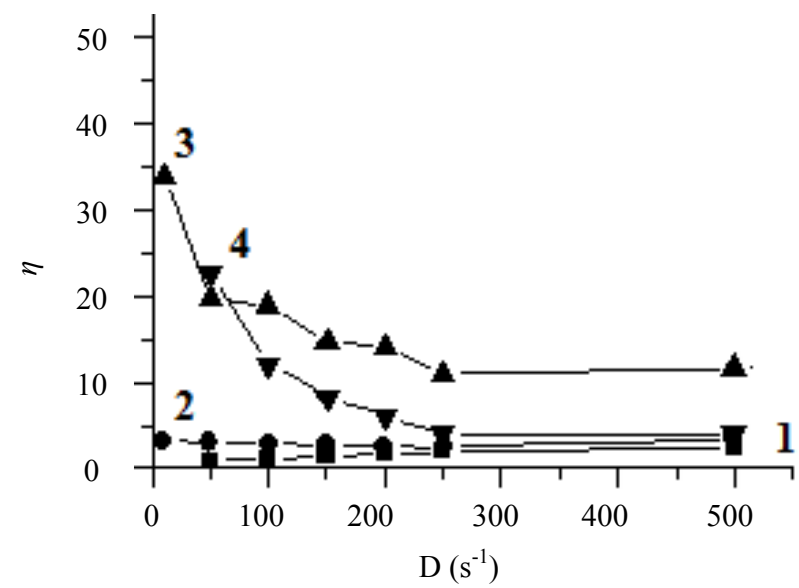

Fig. 3 Viscosity (mPa·s) shear rates of $\mathrm{BaTiO}_{3}$ suspensions in acetylacetone-ethanol with different solid OP (mas.\%): $1-0.01 ; 2-0.05 ; 3-0 ; 4-0.2$.

to EPD process (Fig. 3).

The zeta potential at this level is shown in Fig. 4. It presents the zeta potential that reaches a maximum value when added amount OP about 0.05 wt.\%. This is explained by the formation of OP adsorption shell (charged micelle) on the surface of barium titanate particles that will contribute to the motion of particles in EPD process. The $\mathrm{pH}$ medium was varied from values 4 to 10 and electric conductivity region of $1.5 \times$ $10^{-5}-4.4 \times 10^{-7} \mathrm{~S} / \mathrm{cm}$. The authors note that relationship between of $\varsigma(\mathrm{mV})$ and amount of OP is close to phosphoester (0.4-1.6 wt.\%) in suspension of PZT [14].

\subsection{EPD of $\mathrm{BaTiO}_{3}$ Suspensions}

In the EPD process, the same suspension concentrations used for rheological characterization were in order to evaluate the combined influence of suspension concentration, voltage on the quality of $\mathrm{BaTiO}_{3}$ deposites by EPD. The experiments were carried out at constant room temperature. The investigation influence of solid $\mathrm{BaTiO}_{3}$ (wt.\%) on EPD process of suspensions with $0.05 \%$ OP at different time deposition and electric field strength of $100 \mathrm{~V}$ presents in Fig. 5. The results show that effective mass deposition is for suspension with $2 \mathrm{wt} . \%$ of $\mathrm{BaTiO}_{3}$ because of higher value of $\varsigma(\mathrm{mV})$ particles.

It can been seen that when the particle concentration in the suspension is higher the mass deposition is lower. It may be due to the high level of non-uniformity of the deposited particles under very high driving forces. It is also noted that the deposition and time relationship sometimes has an non-linear appearance. Similar observation has been reported in Refs. $[1,13,15]$ and this is attributed to the change in deposition rate and particle concentration as deposition continues.

The best quality films were obtained using 2 wt.\% solids suspensions with $0.05 \%$ of OP. SEM micrographs of $\mathrm{BaTiO}_{3}$ coatings electrophoretically

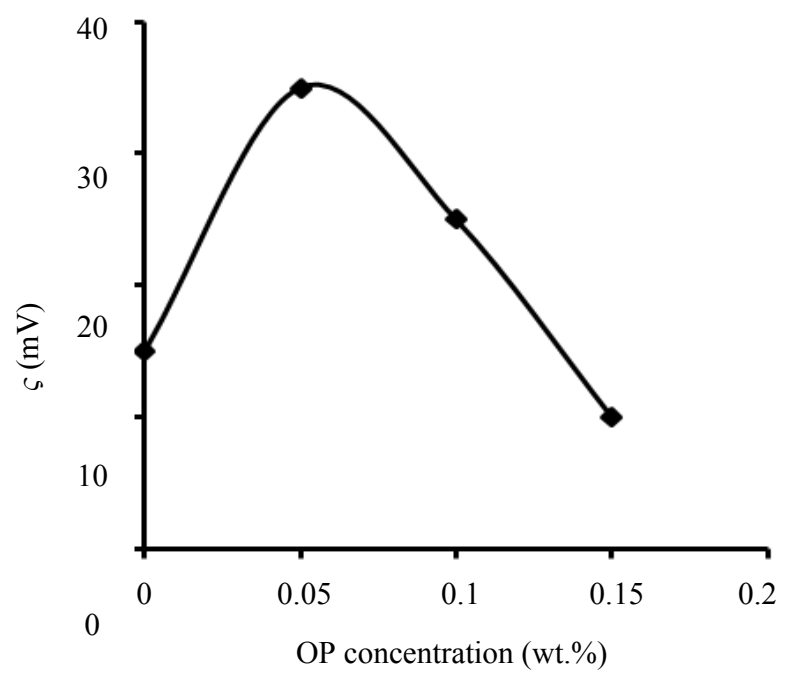

Fig. 4 Relationship between zeta potential ( $\varsigma$ ) of $\mathrm{BaTiO}_{3}$ and the amount of added olygoperoxide (OP).

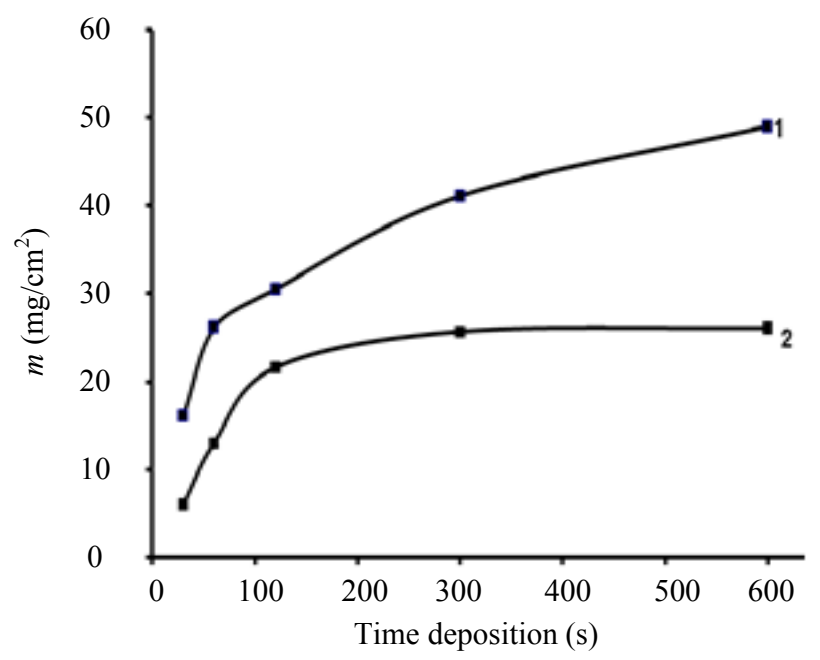

Fig. $5 \mathrm{BaTiO}_{3}$ mass deposited $\left(\mathrm{mg} / \mathrm{cm}^{2}\right)$ as a function of the time deposition from the suspension of different concentration (mas.\%): 1- 2, 2-10. 


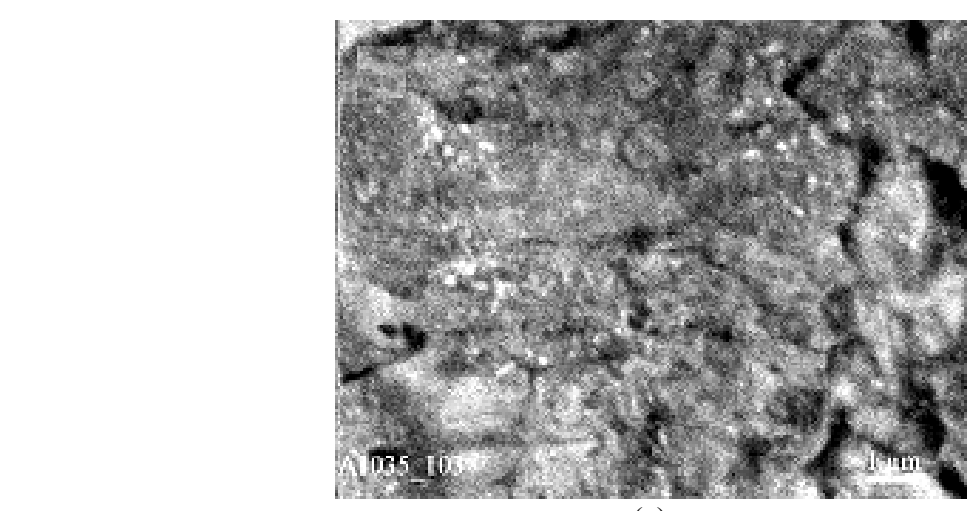

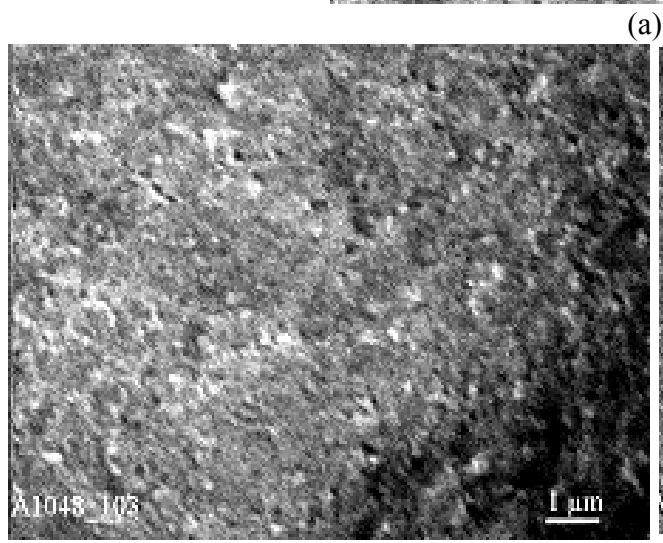

(b)

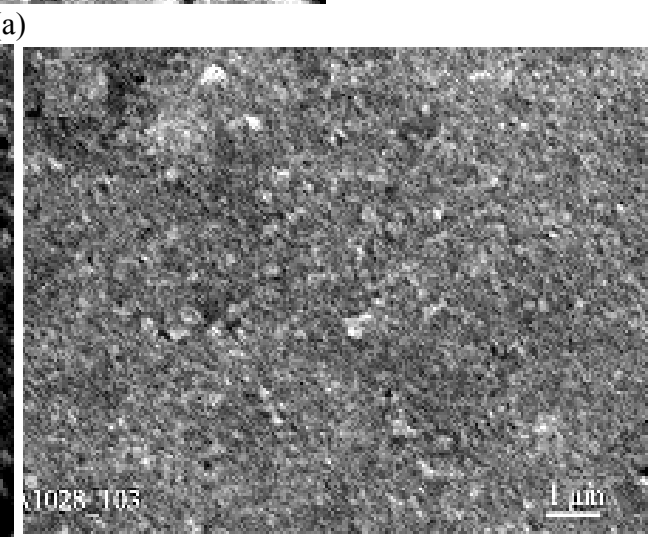

(c)

Fig. 6 SEM micrographs of $\mathrm{BaTiO}_{3}$ coatings by EPD on Ni substrate at (a) $5 \mathrm{~V}$, (b) $50 \mathrm{~V}$, (c) $100 \mathrm{~V}$ and time deposition $60 \mathrm{~s}$.

deposited at 5, 50, $100 \mathrm{~V}$ (drying $100{ }^{\circ} \mathrm{C}$ ) $60 \mathrm{~s}$ are shown in Fig. 6. In contrast, at $5 \mathrm{~V}$ the coatings developed microcracks (Fig. 6a). By performing EPD at $50 \mathrm{~V}$ and $100 \mathrm{~V}$ dense and uniform films were obtained as shown in Fig. $6 \mathrm{~b}$ and 6c, respectively.

\section{Conclusions}

It was shown that at surfactant concentration (OP) of $0.05 \mathrm{wt} . \%$ the value $\zeta$ of particles increases and viscosity suspensions reduces (Newtonian flow behavior). The obtained results show that the ball milling effect on to the suspensions also helps to introduce more protons from the organic solvent which is attached to the surface of the $\mathrm{BaTiO}_{3}$ powder thus improving its deposition.

Moreover due to concentration of 2 wt.\% a good-quality $\mathrm{BaTiO}_{3}$ deposites on planar Ni substrates, as observed by SEM, were obtained by EPD using voltage $100 \mathrm{~V}$ and $60 \mathrm{~s}$ deposition time. It is very important to achieve crack-free and smooth $\mathrm{BaTiO}_{3}$ coatings before sintering process.

\section{Acknowledgments}

The authors would like to thank Ph.D. Zaichenko Alexander and his coworkers (Lvivsky Politechnik University of Ukraine) for unique synthesized surfactant OP with characteristics which was used in EPD suspensions.

\section{References}

[1] Jun, B. Preparation of $\mathrm{ZnO}$ Thin Film by Electrophoretic Deposition (EPD). J. Korean. Ceram. Soc 2012, 49, 78-83.

[2] Ghrairi, M.; Bouaicha, M. Structural, Morphological and Optical Properties of $\mathrm{TiO}_{2}$ Thin Films Synthesized by the Electrophoretic Deposition Technique. Nanoscale. Research. Let. 2012, 7, 357-364.

[3] Antonelli, E.; Silva, R. S.; De Vicente, F. S.; et al. Electrophoretic Deposition of $\mathrm{Ba}_{0.77} \mathrm{Ca}_{0.23} \mathrm{TiO}_{3}$ Nanopowders. J. Mater. Pross. Technol. 2008, 203, 526-531.

[4] Lough, R. F.; Hong, J. Y. Electrophoretic Deposition of Insulation Layers for Termination Process of PNN-PZT 
Multilayer Actuator. Mult. Electron. Ceram. Dev. Ceram.Trans. 1999, 97, 355-366.

[5] Lough, R. F.; Hsu, Y. H. Fabrication of Barium Titanate Ferroelectric Layers by Electrophoretic Deposition Trechnique. Mater.Chem.and Phys. 2003, 79, 226-229.

[6] Barbosa, J. G.; Pereira, M. R.; Moura, C.; Mendes, J. A.; Almeida, B. G. Barium Titanate Thin Film Deposited by Electrophoresis on p-doped $\mathrm{Si}$ (100) Substrates. J. Nanosci. Nanotechnol. 2011, 11, 8700-4.

[7] Kim, Y.; Jun, B. Suspension Stability of $\mathrm{BaTiO}_{3}$ Nanoparticles under Electrical Applied Field. Mater. Sci. Forum. 2007, 544-545, 139-142.

[8] Harari, B. Development of High Capacitance Films for Electrical Energy Storage Using Electrophoretic Deposition of $\mathrm{BaTiO}_{3}$ on Ultrasonically Etched Ni. Thesis. 2012, 1-136.

[9] Wu, Y. J.; Tanaka, S.; Li, H.; Kuwabara M. Preparation of Nano-structured $\mathrm{BaTiO}_{3}$ Thin Film by Electrophoretic Deposition and Its Characterization. J. Europ. Ceram.
Soc. 2005, 25, 2041-2044.

[10] Xue, L.; Yan, Y. Preparation of Oriented Barium Titanate thin film by Combination of Electrophoretic Deposition with Hydrothermal Treatment. J. Mater. Sci. Technol. 2010, 26, 996-1000.

[11] Ragulya, A. V.; Polotay, A. V. Non-isometric Sintering of Barium Titanate Nanopowders of Different Origination. Ferroel. 2001, 254, 41-45.

[12] Mistler, R. E.; Twiname, E. R. Tape Casting, Theory and Practice. Amer. Ceram. Soc. 2000.

[13] Santillan, M. J.; Membrives, F.; Quaranta, N.; Boccaccini, A. R. Characterization of $\mathrm{TiO}_{2}$ Nanoparticle Suspensions for Electrophoretic Deposition. J. Nanopart. Res. 2008, 10, 787-793.

[14] Sakka, Y.; Uchikoshi, T. Forming and Microstructure Control of Ceramics by Electrophoretic Deposition (EPD). KONA Powder and Particle J. 2010, 28, 74-90.

[15] Ma, J.; Cheng, W. Deposition and Packing Study of Sub-micron PZT Ceramics using Electrophoretic Deposition. Mater. Lett. 2002, 56, 721-727. 